Copyright

by

Hyunkyu Jang

2017 
The Dissertation Committee for Hyunkyu Jang Certifies that this is the approved version of the following dissertation:

\section{Answering for Yourself versus Others:}

\section{Direct versus Indirect Estimates of Charitable Donations}

\section{Committee:}

Julie R. Irwin, Supervisor

Rajagopal Raghunathan

Ty Henderson

Adrian F. Ward

Brian Richter 


\title{
Answering for Yourself versus Others: \\ Direct versus Indirect Estimates of Charitable Donations
}

by

Hyunkyu Jang, B.Arts.; B.B.A.; M.S.

\author{
Dissertation \\ Presented to the Faculty of the Graduate School of \\ The University of Texas at Austin \\ in Partial Fulfillment \\ of the Requirements \\ for the Degree of \\ Doctor of Philosophy
}

The University of Texas at Austin

May 2017 


\section{Dedication}

I dedicate this dissertation to my family. To my wife, who has sacrificed her career to support me in my pursuits for the past five years, which is even longer than the three years I spent waiting for her to say "yes" after I first asked her to go out with me. Now I owe her two years. To my first-born son, the only person among my friends and family who has not yet agreed to my becoming a professor. He has been waiting his whole 31month life for his daddy to graduate and be able to spend 24 hours a day with him. He no doubt felt betrayed when he first heard that I would become a professor and would still need to go to campus. At least that's how I interpreted his puckered lip and little tears. To my second son, who is now seven months old, who willingly and happily agreed with my being a professor while I was holding him up, shaking him, and kissing him multiple times on his chubby cheeks. To my father, my mother, and sister in Korea, who have never stopped thinking of me and praying for me. 


\section{Acknowledgements}

I prayed for two things before I left Korea to come to Austin: for a good advisor for my academic life and for a good church community for my spiritual life.

Julie Irwin was the answer to my first prayer. I am grateful to have worked with someone who seems to think and sometimes says that I'm smart, especially as my memories of doing well in the past gradually faded along with my self-confidence. I am

lucky and proud to belong to Julie's exclusive club of students, full of many productive researchers. I have learned a lot from her, but I'm sure I still have a lot to learn.

I only asked for one person, but I was given two more people as a bonus who always viewed me positively and recognized my potential. Leigh McAlister has cheered me on, saying that I will make a great researcher. When I occasionally had meals with her, she would give me valuable advice, always wanting to help me to have long-term success in this field. Her sincerity made me want to become a great researcher to repay her kindness and meet her expectations. Elaine Massock was another stroke of luck for me. She is a lawyer, but rather than representing me in court, helped my ideas, confined in my poor English prison, to be released in my papers and presentations.

The leaders of my church group, BJ Min and Seungmin Lee, were the answers to my second prayer. I could not have survived my five years in the program without their supports. I also thank my committee members, Raj Raghunathan, Ty Henderson, Adrian Ward, and Brian Richter for their invaluable advice on my work. I wish to acknowledge all of these fine people and their contributions to this work. 


\title{
Answering for Yourself versus Others: Direct versus Indirect Estimates of Charitable Donations
}

\author{
Hyunkyu Jang, Ph.D. \\ The University of Texas at Austin, 2017
}

Supervisor: Julie R. Irwin

It is common for researchers in marketing and other social sciences interested in ethical behavior such as propensity to donate to a charity to ask "indirect" questions about others (e.g., "what would another student donate?") in order to measure respondents' own propensity to donate. The idea is that people project their own desires onto their responses about others and that they are more likely to admit a lower level of generosity when they are under the lessened social pressure of the indirect question. In these four studies, we measure estimates respondents make about self (self-estimates) and others (other-estimates) as well as their actual donations to charity, doing so at an individual level to challenge the prevailing wisdom that indirect responses are more accurate and useful for research than direct responses. I conceptualize accuracy in terms of both the mean and correlations. I show that although mean-level results sometimes show other-estimates to be closer to actual behavior, they are not consistently so, and explain this inconsistency; and further, that correlations show self-estimates to always better reflect actual donations than other-estimates. These results support the use of selfestimates in the ethical domain and argue against the existence of projection in marketing research donation responses. 


\section{Table of Contents}

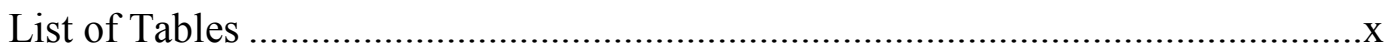

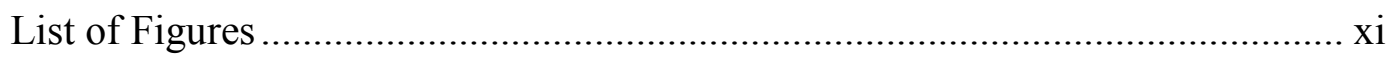

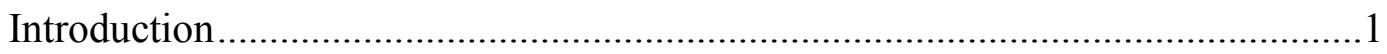

Conceptual Background..............................................................................

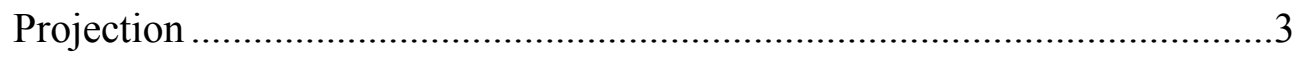

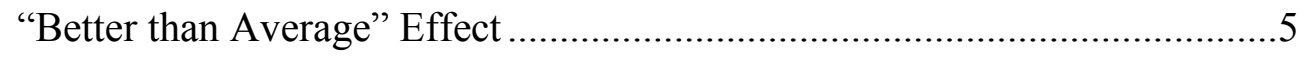

Research Showing Better Mean-Level Predictability for Direct (versus Indirect)

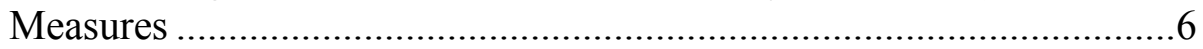

Mean- versus Individual-Level Data ......................................................8

Mean versus Correlational Accuracy ........................................................ 12

Gathering Self-estimates, Other-estimates, and Actual Donations...............14

Serial Tracking Method ...................................................................... 15

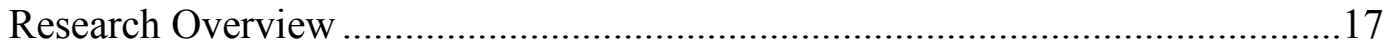

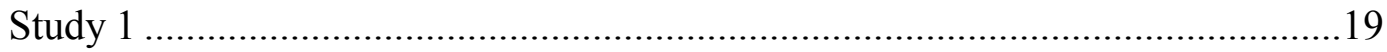

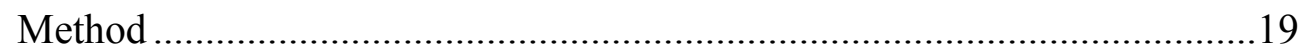

Participants and design .........................................................19

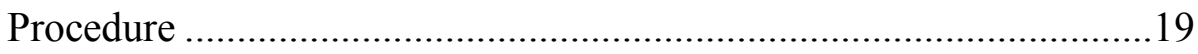

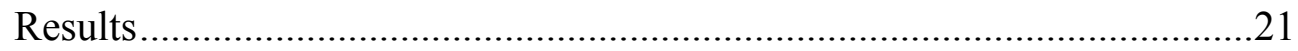

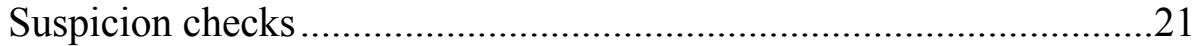

The influence of pre-estimation on actual donation .........................22

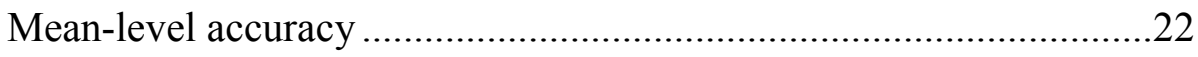

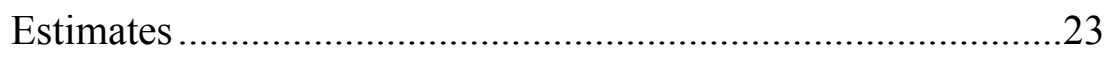

Deviations from Actual.......................................................23

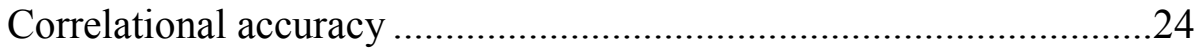

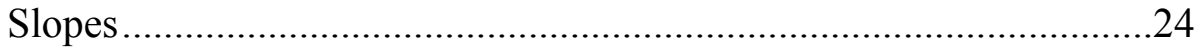

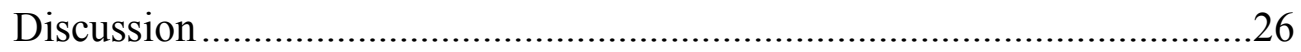




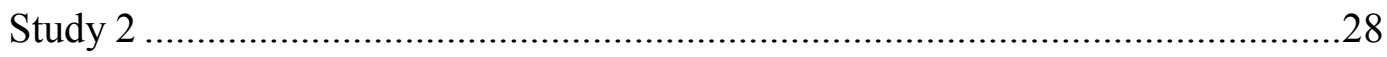

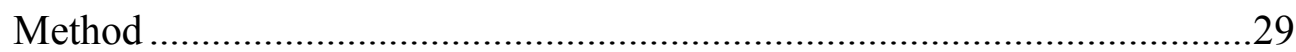

Participants and design ...................................................................29

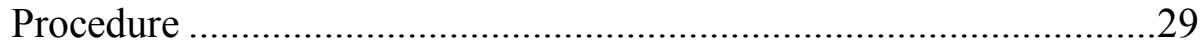

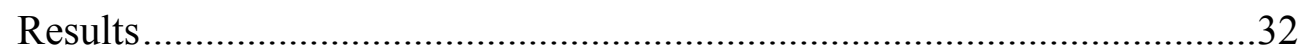

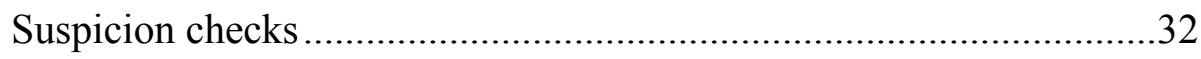

Mean-level accuracy ...........................................................................

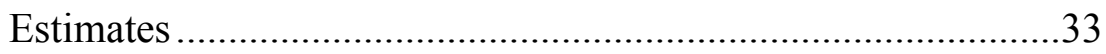

Deviations from Actual................................................................

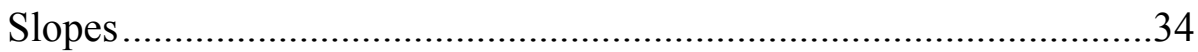

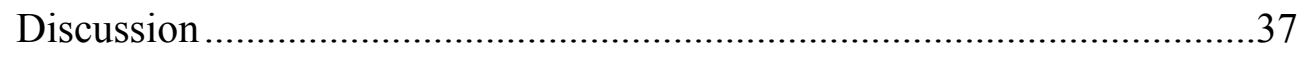

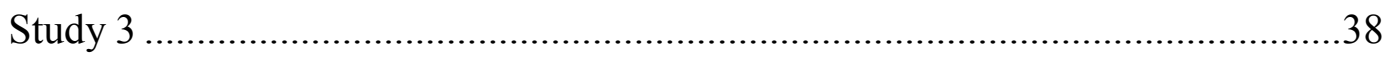

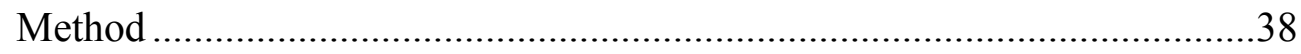

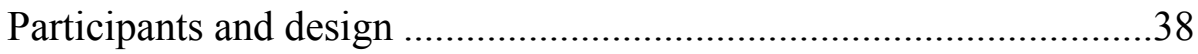

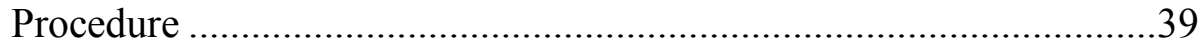

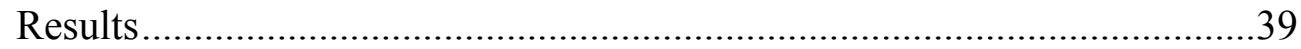

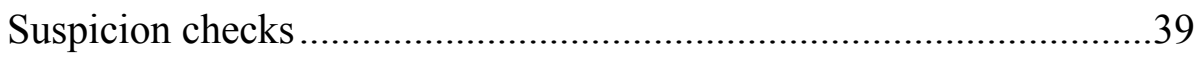

Mean-level accuracy ……………………………………………......... 40

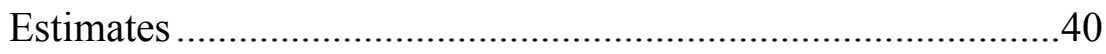

Deviations from Actual.............................................................41

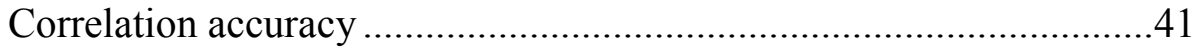

Slopes

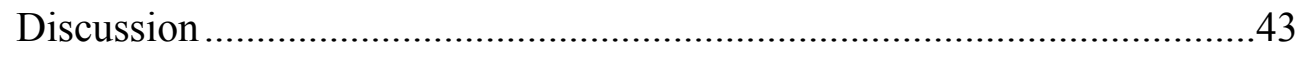

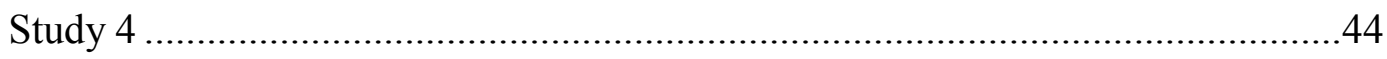

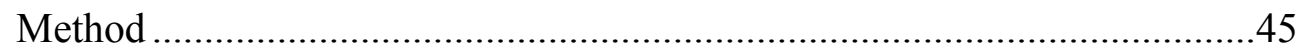

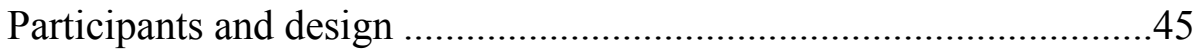

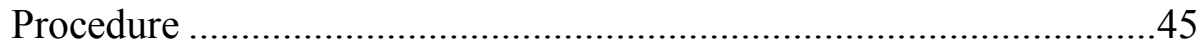

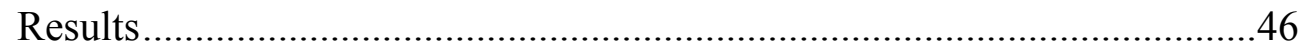

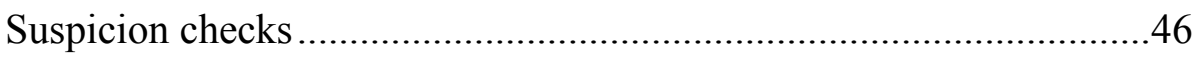

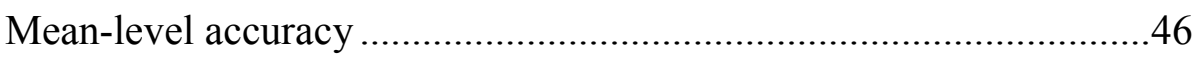




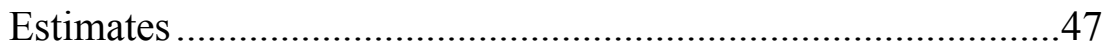

Deviations from Actual......................................................4 47

Correlation accuracy .............................................................47

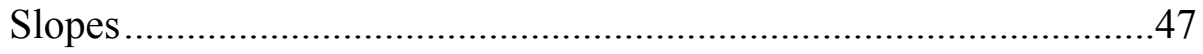

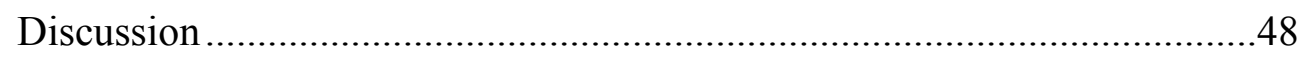

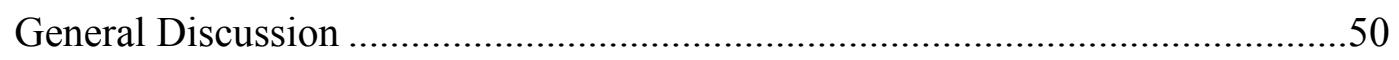

Contributions................................................................................... 51

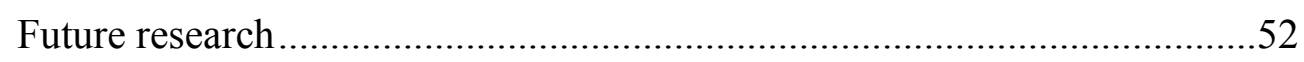

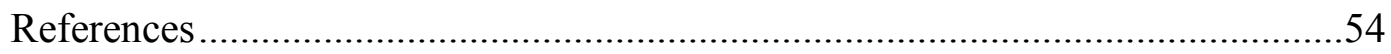




\section{List of Tables}

Table 1: Predictions by Different Theories ......................................................14

Table 2: $\quad$ Study 1 - Mean Estimates/Actual Responses and Correlations of

Estimates with Actual Behavior........................................................23

Table 3: $\quad$ Study 2 - Mean Estimates/Actual Donations and Correlations of

Estimates with Actual Donations.....................................................34

Table 4: $\quad$ Study 3 - Mean Estimates/Actual Donations and Correlations of

Estimates with Actual Donations.......................................................41

Table 5: $\quad$ Study 4 - Mean Estimates/Actual Donations and Correlations of

Estimates with Actual Donations.........................................................47 


\section{List of Figures}

Figure 1: Hypothesis - Self- and Other-Estimates versus Actual Donations...11

Figure 2: $\quad$ Study 1 - Self- and Other- Estimate Lines ................................25

Figure 3: $\quad$ Study 2 - Self- and Other- Estimate Lines ...................................35 


\section{Introduction}

Managers and marketing researchers often ask respondents about their anticipated future ethical behavior. Donations to charity, in particular, are an especially ubiquitous type of ethical market activity, of interest both theoretically and practically. In 2014, Americans donated $\$ 358$ billion or 2.1 percent of the U.S. GDP (Giving USA, 2015), twenty-three times the amount of U.S. game software sales that year (Entertainment Software Association, 2015), and nine times the U.S. smartphone market size (Statista, 2016). Charitable donations, besides being big business, are arguably the most sizable and one of the purest expressions of consumer ethics and pro-social behavior in the marketplace, a fact which is reflected in the great interest in the topic among consumer researchers (e.g., Anik, Norton, \& Ariely, 2014; Lee, Winterich, \& Ross, 2014; Small \& Verrochi, 2009).

The simplest way to measure future behavior is to ask direct questions about a person's intention to engage in the specific behavior, such as "How much would you donate?" However, indirect questions, which commonly take the form of asking how people think others would behave in the same situation (e.g., "How much do you think others would donate?"), have often been recommended as better measures of actual sensitive behavior (Fisher, 1993; Lusk \& Norwood, 2010). The idea is that when people answer indirect questions they are likely to project their own propensities on the other, and thus be more honest than they might be when under the social pressure to inflate their generosity (Fisher, 1993).

Despite the frequent use of indirect questions, the projective technique theory has

not, to my knowledge, been verified directly. Researchers have not tested the validity of indirect questions by measuring actual behavior and comparing it to responses to direct 
and indirect questions. Without data about actual behavior, I cannot be sure if actual behavior is really closer to responses to indirect questions than it is to responses to direct questions. Even more crucially, without actual behavioral data, it is impossible to distinguish between mean-level accuracy and discriminatory/correlational accuracy. In this paper, I attempt to correct for these gaps in the literature. 


\section{Conceptual Background}

\section{ProjeCtion}

Indirect questions, such as asking survey respondents about what others might do, think, or feel, have been used in research to identify what respondents themselves will do, think, or feel, especially when researchers are worried that respondents will not be honest due to social pressure to be more ethical or generous than they actually are. This practice of asking indirect questions is based on the projection theory, which claims that thoughts about others are actually a reflection of a respondent's thoughts about themselves (Fisher, 1993; Holmes, 1968).

Fisher (1993) in particular is often cited as a source for using indirect questions to reduce the social desirability bias in marketing research. Many researchers have cited his paper and used indirect questions to measure prosocial and/or (un)ethical behavior across the social sciences in contexts such as purchasing ethically-produced products (Luchs, Naylor, Irwin, \& Raghunathan, 2010; Lusk \& Norwood, 2010; Olynk, Tonsor, \& Wolf, 2010), purchasing counterfeit products (Wilcox, Kim, \& Sen, 2009), donating blood (Lacetera \& Macis, 2010), downloading pirated music (Chiou, Cheng, \& Huang, 2011; Sinha \& Mandel, 2008), hiring people with disabilities (Kaye, Jans, \& Jones, 2011), reporting unethical behavior in the workplace (D. L. Miller \& Thomas, 2005), and reporting mistakes by retailers (i.e., receiving too much change, Steenhaut \& Van Kenhove, 2005).

The use of indirect questions has also extended to many practical forums. For example, a popular research methods website $^{1}$ recommends indirect questions over direct

\footnotetext{
1 http://www.socialresearchmethods.net/kb/quescont.php
} 
questions for questionnaires, stating, "You might get reasonable estimates if you ask the respondent how much money 'people you know' typically give in a year to charitable causes."

In defending the use of indirect measures, researchers have pointed out that responses to indirect questions yielded answers in their studies that were less socially desirable (e.g., smaller donations, higher risky behavior) than responses to direct measures. They used mean-level measures of respondents' answers to indirect and direct questions and inferred that the indirect responses were closer than the direct responses to what the respondents would actually have done. Surprisingly, this projective technique inference has not been tested, to my knowledge, by comparing responses to actual behavioral data to show whether direct or indirect measures yield more accurate measures of what respondents will actually do.

Instead of measuring actual behavior, a few studies in the projective technique literature used proxies to determine the true value of a respondent's traits, either a factor score generated based on a factor analysis or peer evaluation. Fisher and Tellis (1998) used factor analysis. They asked direct questions ( "It's very important TO ME that others approve of my purchase of each of the following five products") and indirect questions ("It's very important TO THE TYPICAL STUDENT that others approve of his or her purchase of each of the following five products") for five different products. They then ran a factor analysis with five responses to direct questions and five responses to indirect questions to generate true scores. They assumed "variance that is common to both the direct and indirect items provides an estimate of the underlying true score," so they used the factor score as an estimate of each respondent's underlying true score. Because they found the factor loadings for other-estimates were greater than those for self-estimates and other-estimates were more highly correlated with those true scores, they concluded 
that other-estimates are more strongly associated with true values than are self-estimates. Some other studies (Rokeach 1945, Sears 1936, Wells and Goldstein 1964) used peer ratings as a proxy for true values. For example, in studies by Sears (1936), participants rated themselves and others on many traits. The average ratings for a specific participant were considered true values for that participant's trait. If other peers said that person A's level of generosity was 6 on a 7-point scale, 6 was used as his true degree of generosity. This number was compared with participants' self-estimates and the participants' otherestimates about generosity. However, it is an illogical application of the projective technique theory to use such peer evaluations as projected true values for participants because those peers also would have projected themselves onto the participants when evaluating them.

\section{“BetTer THAN AVERAGE" EFFECT}

Besides projection, another research stream related to this question is the research on what is commonly termed the "better than average effect" (Balcetis \& Dunning, 2013; Balcetis, Dunning, \& Miller, 2008; Epley \& Dunning, 2000). These studies used indirect questions as a representation of what participants thought about others, used direct questions as a representation of what participants thought about themselves, and compared both to mean-level data about actual behavior. The comparison to actual behavior provided some basis for verifying which responses better approximated actual behavior, other-estimates in response to indirect questions or self-estimates in response to direct questions, although the so-called "holier-than-thou" researchers (e.g., Epley \& Dunning, 2000) assumed indirect questions would reveal participants' actual views about others rather than revealing the participants' own views (as projection theorists believed 
would be the case). Many studies in this literature took the mean response of participants' other-estimates and the mean response of their self-estimates and concluded that otherestimates were closer to actual behavior than were self-estimates, explaining that a participant's reasoning about other people was more likely to consider base rates (i.e., expected averages) than when reasoning about themselves (Kahneman \& Tversky, 1979). For example, Epley and Dunning (2000) explained that predictions about how much others would donate ( $\$ 1.83$ out of $\$ 5$ ) were closer on average to actual donation amounts (\$1.53) than were predictions about how much they would themselves donate $(\$ 2.44)$ because people were able to envision the average donation amount in the other-condition but used individuating information about themselves in the self-condition. These findings are consistent with conclusions reached by projection-based indirect question proponents, assuming that using mean-level data leads to sound conclusions. Thus, this set of findings appeared to put an end to inquiry in the literature into the superiority of indirect questions to predict donation behavior.

\section{Research Showing Better Mean-Level Predictability for Direct (Versus INDIRECT) MEASURES}

There is some reason to doubt the consensus about the value of indirect judgments. A few studies (e.g., Goethals, 1986; D. T. Miller \& Ratner, 1998; Teper, Inzlicht, \& Page-Gould, 2011; Teper, Tullett, Page-Gould, \& Inzlicht, 2015) comparing actual behavior to either average self- or other- estimates found self-estimates to be superior to other-estimates, inconsistent with the conclusion previously drawn in the majority of studies both inside and outside of the projective-theory domain. In the Teper et al. $(2011,2015)$ study, students were either in an action condition, in which they took a test and had opportunities to cheat, or they were in a prediction condition, in which they 
predicted how much they would cheat. The findings were that those in the action condition actually cheated less on a math test than those in the prediction condition said that they would cheat. In other words, they found actual behavior to be more socially desirable than self-estimates in this moral context. If other-estimates were less socially desirable than self-estimates, actual behavior would be found to be closer to selfestimates than other-estimates. The researchers in the Teper et al. $(2011,2015)$ studies did not ask participants to predict other students' cheating behavior, so it is inconclusive whether other-estimates were less socially desirable than self-estimates. However, given that other research has shown that other-estimates are often less socially desirable than self-estimates (see Katz \& Allport, 1931 for such an example in cheating behavior), it is reasonable to conclude from the Teper et al. $(2011,2015)$ work that the mean selfestimate response would be closer to actual behavior than the mean other-estimate response.

Another research stream is found in work on the "norm of self-interest." Miller and Ratner (1998) found that self-estimates for prosocial behavior (in one study, 63\% would donate blood) were more socially desirable than other-estimates $(33 \%$ of others would) in their first four studies. Based on these results, they concluded that people believe others are more influenced by self-interest than they are, so they predict others' behavior to be more selfish than their own. They suggested that the results would hold true even if they replaced self-estimates with actual behavior because they believed that self-estimates accurately reflected actual behavior. To prove this and address concerns that those higher self-estimates might simply be due to the social desirability bias, they conducted a fifth study, where they measured the actual behavior of all students instead of self-estimates. They compared the actual behavior to other-estimates how students assessed others and found the same pattern in the other studies. Goethals (1986) reached 
a result similar to Miller and Ratner (1998) in one field study in which Goethals measured actual behavior and compared it to other-estimates in the blood donation context. $60 \%$ of students who were asked to donate blood actually agreed to do so, and they predicted that $35 \%$ of other students would donate blood.

Because these are very different research streams, no one to my knowledge has noted this important and confounding contrasting pattern between studies finding that the average of other-estimates is closer to actual behavior and studies finding the average of self-estimates more closely reflect actual behavior. What would help disentangle this inconsistency?

\section{MEAN- VERSUS INDIVIDUAL-LEVEL DATA}

Most of the findings I have outlined so far have been based on mean-level data and most arguments about indirect measures have focused on these averaged responses, especially those applying the projection theory, by far the most popular theory. Only a few studies (e.g., Fisher \& Tellis, 1998) have relied on correlations. I suggest that the seemingly contradictory findings in the literature may be better understood if researchers concentrate on individual-level data and take into account the patterns among selfestimates, other-estimates, and actual behavioral data across the entire range of data. I make the following proposition based on observation from prior research findings, which I will discuss shortly:

Proposition: The pattern of self- versus other-estimates relative to actual donation behavior is unlikely to be consistent across the range of actual donation values. Thus, for 
some datasets there may be one pattern and for others another simply because the data have different distributions of donation amounts.

One observation from prior research findings is that researchers who found otherestimates to be closer to actual behavior than self-estimates tended to have data sets where actual behavior was less socially desirable, that is, for example, actual donations were lower than both self- and other-estimates (e.g., Epley \& Dunning, 2000), whereas some other researchers found actual behavior to be more socially desirable than otherestimates (e.g., Goethals, 1986; D. T. Miller \& Ratner, 1998) or than self-estimates (e.g., Teper et al., 2011, 2015). If actual behavior is lower (and therefore less socially desirable) than either self- or other-estimates, it is highly likely that actual behavior will be closer to other-estimates than self-estimates because prior research on the better-thanaverage effect has repeatedly shown that other-estimates are generally lower (or less socially desirable) than self-estimates. In the same way, if actual behavior is higher (or more socially desirable) than self-estimates, actual behavior will be closer to selfestimates than other-estimates. In studies where the researchers found actual behavior to be closer to other-estimates than to self-estimates, actual behavior tended to be lower (or less socially desirable) than either self- or other-estimates. For example, Epley and Dunning (2000) reported that "most participants used the miserly end of this scale... creating a positively skewed distribution." In that study, most donors were small donors, so actual donations $(\$ 1.53)$ were smaller than both self-estimates $(\$ 2.44)$ and otherestimates (\$1.83). Since, consistent with the better-than-average effect, other-estimates were lower than self-estimates and actual was lower than both self- and other-estimates, actual donations were closer to other-estimates than to self-estimates. 
What if actual behavior is more socially desirable than self-estimates? In that case, it will be impossible for both the better-than-average effect and Dunning and colleagues' findings to be true. In order for the better-than-average effect to be true, actual behavior would have to be closer to self-estimates than to other-estimates, contrary to Dunning and colleagues' findings. In order for Dunning and colleagues' findings to be true, other-estimates would have to be more socially desirable than self-estimates, contrary to the better-than-average effect. However, Teper et al. $(2011,2015)$ actually found that actual behavior was more socially desirable than self-estimates. In their studies, the average of actual behavior in all studies was at the upper end of the spectrum. For example, in study 1 (Teper et al. 2015), participants predicted they would cheat on 3.89 out of 15 questions, but they only actually cheated on an average of 1.19 questions out of 15 questions; the standard deviation of actual behavior was 3.02, which implies that most students were zero-question or one-question cheaters. Based on this discussion about prior research findings, I suggest that the accuracy of mean estimates depends on the level of actual donations. Thus, mean-level comparisons will bounce around across datasets depending on the distribution of responses. I will argue that self-estimates are more highly correlated with actual donations than other-estimates. The higher correlations between self-estimates and actual donations means that when self- and otherestimates are plotted against actual donations, the result is steeper self-estimate lines than other-estimate lines. This hypothesis is expressed via an illustrative graph, in Figure 1. It becomes clear that the pattern of self- versus other-estimates relative to actual donation behavior is not consistent across the range of actual values when measured in terms of mean-level data. The self-estimate line is closer to the perfect prediction line at the high end, but is further away at the low end. If small donors at the low end are a large portion of participants (i.e., positively skewed distribution), actual donations will be lower than 
both self- and other-estimates, so other-estimates will appear to be closer to actual donations on average. In contrast, if most participants donate large amounts (i.e., negatively skewed distribution), actual donations will be higher than both estimates, so now self-estimates will appear to be closer to actual donations than other-estimates. This pattern can explain why some researchers who had positively skewed distributions in their data sets (e.g., Epley \& Dunning, 2000) found that other-estimates were closer to actual behavior than self-estimates, whereas some researchers who had negatively skewed distributions (e.g., Teper et al., 2015) found that actual behavior was more socially desirable than self-estimates. This suggests the unreliability of mean-level measurements in assessing self- and other-estimates.

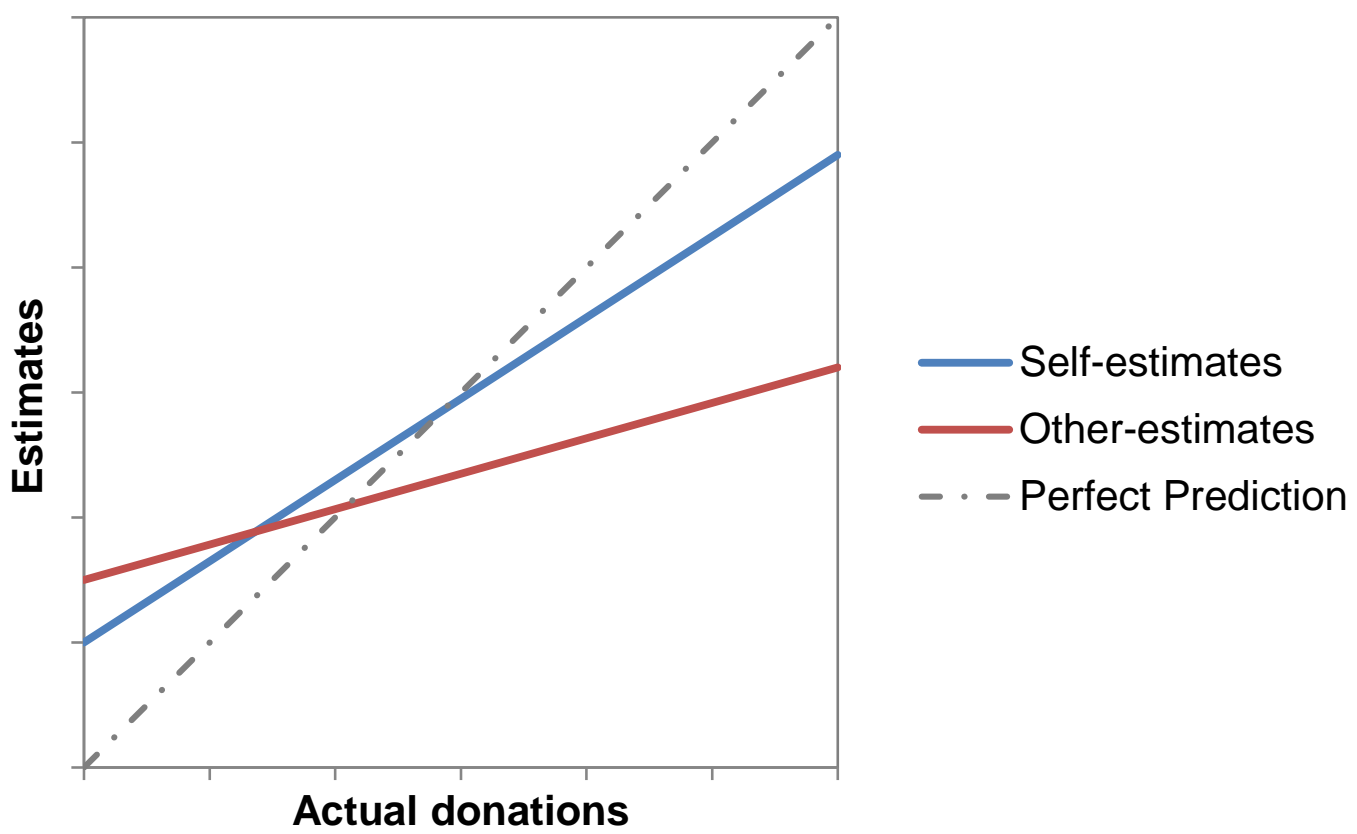

Figure 1: Hypothesis - Self- and Other-Estimates versus Actual Donations 


\section{Mean versus Correlational ACCuracy}

The pattern illustrated in Figure 1 is not consistent with the belief of projective technique theorists in that the pattern suggests that other-estimates are not always closer to actual behavior at the mean level, and that self-estimates are in fact more highly correlated with actual behavior than other-estimates. Projective technique theory would predict other-estimates to be both closer to and more highly correlated with actual behavior. Fisher argued that indirect questions were better than direct questions whether using mean-level measures (Fisher 1993) or correlational measures (Fisher and Tellis 1998). To examine whether the pattern illustrated in Figure 1 is true or not, it is critical to identify both the mean (i.e., the intercept in a multiple regression) and also the correlation (i.e., the degree of fit in a multiple regression, a combination of the slope and any error). The degree of accuracy in any estimate can be construed as a combination of these two components (Dunning \& Helzer, 2014; Epley \& Dunning, 2000): mean-level prediction accuracy and correlational prediction accuracy.

Using both mean and correlational accuracy will be useful in determining which theory is valid given that different theories take different views on mean and correlational accuracy (see Table 1). None of the different theories about indirect versus direct measures have traditionally conceptualized the problem in terms of both mean and correlational data; thus, outlining what I believe to be the expectations of each could prove useful in explaining why previous results seem inconsistent and how my studies clarify these inconsistencies and determine the superiority of direct versus indirect questions. Correlational accuracy will be especially helpful in distinguishing the theory of Dunning and colleagues (Balcetis \& Dunning, 2013; Balcetis et al., 2008; Epley \& Dunning, 2000) and the projection theory; both camps of researchers have predicted the 
same mean-level results, but each bases its predictions on a different theory. In other words, mean-level results cannot distinguish the two different theories.

The projective technique theory arises from techniques originally developed for psychoanalysts (e.g., Freud, 1938) and assumes that people project their own attitudes and behavior onto others. If it is true across the board that other-estimates are closer to a person's actual behavior than that person's own self-estimates, as the projection theory posits, then other-estimates should be closer to actual behavior whether applying meanlevel measures or correlational measures. Therefore, even if mean-level measures seemed to indicate indirect questions were better, unless correlational measures also indicated that to be true, one cannot conclude that projective technique theory is valid. Dunning and colleagues predict other-estimates to be closer to actual behavior at the mean-level, but less correlated with actual behavior at the individual level. Epley and Dunning (2000) used Kahneman and Tversky's (1979) work on comparative judgments, which suggests that when people make predictions about others, they have insights into the distributional information or the base rate of other people's behavior, so people can accurately predict other people's behavior at the mean-level, whereas when predicting their own behavior, they instead rely on case-specific information (e.g., specific to their personality or character) about themselves. Imagine, for example, an extreme situation in which half of the respondents donate $\$ 0$ and the other half donate $\$ 7$, yielding an average actual donation of $\$ 3.50$. If all of the other-estimates were $\$ 3.50$, they would look accurate even though no one donated $\$ 3.50$. At the individual level, no one's other-estimates would accurately reflect individual actual donations. The fact that everybody gave $\$ 3.50$ as their other-estimates can be suggested as perfect evidence that people have accurate insights on other people's donating behavior, and in that case, it is obvious that people did not project. Only correlational measures can tell us whether people project their actual 
behavior onto others, that is, whether a person's other-estimate reflects that person's actual behavior.

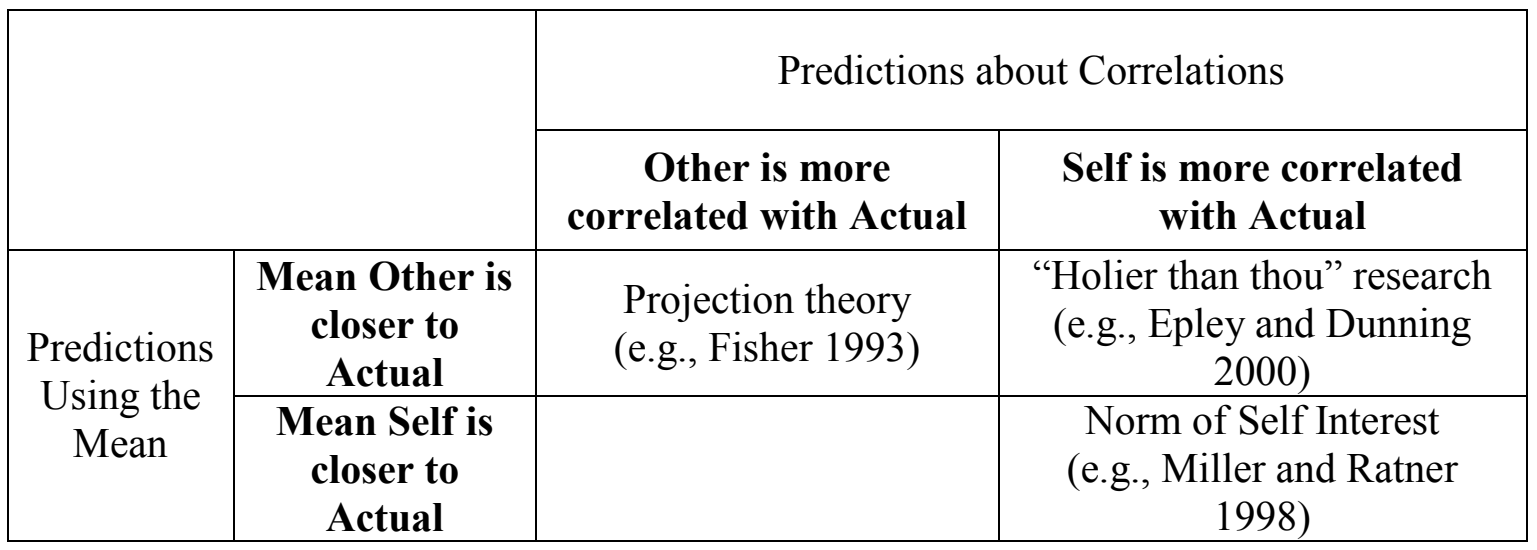

Table 1: $\quad$ Predictions by Different Theories

\section{Gathering Self-estimates, Other-estimates, AND ACtual Donations}

Calculating and comparing correlations requires individual-level data for all three data types: self-estimates, other-estimates, and actual behavior. Note that previous research has not gathered all three measures at an individual level, making it impossible to test the crucial question of which measure is better reflective of actual behavior.

The biggest challenge to the aim of collecting all three measures is collecting individual prosocial-behavioral data in an anonymous environment. The observability of behavior is arguably the strongest influence on prosocial/ethical behavior (Krosnick, 1999). If participants think the experimenter can observe how they actually behave in a given prosocial/ethical situation, they might adjust their behavior accordingly, meaning the experimenter would not obtain accurate values. To this end researchers do their best 
to make sure that participants believe the experimenter will be unable to see how they behave in any given prosocial/ethical situation.

For example, in a typical experiment that provides complete anonymity for donation behavior, participants are given some dollar bills and they can keep all of them or donate as many as they want. They then put any donations in a sealed envelope and leave it in a collection box or return it to the proctor as they exit the experiment room (e.g., Epley \& Dunning, 2000; Lee et al., 2014; Small \& Verrochi, 2009; Smith, Faro, \& Burson, 2013; Winterich, Mittal, \& Ross Jr, 2009). Thus, this method is clever because researchers cannot determine how much each participant donated but rather can only determine the average amount donated; however, it does not reveal individual donation amounts, so it is impossible to calculate correlations of actual behavior to self- or otherestimates. This methodological limitation may explain why there has been no prior empirical research that compared correlations of self- and other-estimates with actual behavior. Rather, numerous prior studies have failed to measure actual behavior, only reporting a positive correlation between self-estimates and other-estimates in research on the false consensus effect (Ross, Greene, \& House, 1977) and on attributive projection (Holmes, 1968). The present article is the first to attempt to link self-, other-, and actual judgments at the individual level in the prosocial/ethical domain.

\section{Serial Tracking Method}

I used a serial number tracking method, developed for this project, to calculate correlations. Unique serial numbers serve as natural identifiers to determine exactly which bills and therefore how much was donated of the total amount provided, as long as 
I keep track of who has which bills while assuring the personal anonymity I assured participants they would have.

More specifically, before the experiment, I recorded the serial numbers of the bills and the seat number of each laptop, behind which each envelope was placed. I then entered the participant's seat number on the first page of the survey that he or she would complete. Through these preliminary steps, I was able to establish links between the donated bills, seat numbers, and survey responses and yet the anonymity of the participants was completely assured, because I did not link their identity with their seat number. Hence, even though participants were asked to put their donation in a collection box placed in a separate and empty room, I was still able to determine how much each one donated. From the participants' perspective, this method appeared the same as the completely anonymous procedures of previous studies. There were no hidden surveillance cameras or marks on donation envelopes that would have led participants to suspect lack of anonymity. Additionally, participants were allowed to donate in 0.5 dollar increments (e.g., $\$ 1.50$ ); if they wanted to donate $\$ 1.50$, they could put one dollar bill in a one-dollar exchange box and take two fifty-cent pieces from another box containing fiftycent pieces. Even though fifty-cent pieces do not have serial numbers, I was able to infer who exchanged a one-dollar bill by tracking the serial numbers of the bills in the onedollar exchange box. 


\section{Research Overview}

Four of my studies examined whether direct or indirect responses were better predictors of future donation behavior in terms of both mean-level and correlational prediction accuracy. In the process, the studies also answered whether projection is a plausible explanation for indirect responses.

In Study 1, participants first predicted how much they and others would donate in a given situation and then made their actual donation decisions. Study 1 also had a control condition in which participants donated without making predictions to eliminate the mere measurement effect (Morwitz \& Fitzsimons, 2004) as an explanation for the results. Study 2 was a test of social pressure: some participants were required to make public to other participants how much they would donate while others kept the information private. The purpose of Study 2 was to see whether direct questions would perform worse under the greater social pressure of public disclosure and whether greater social pressure would affect people differently depending on the amounts donated (i.e., smaller versus larger donors). Study 3 was a test of whether the type of "other" presented in the indirect question made a difference to (1) the mean- and (2) the correlation-level accuracy, to show that it can look as if accuracy has improved simply because the overall mean has changed even though discrimination/correlation is unaffected. In Study 4, I measured how people estimate others' donations and examined whether projection really influences other-estimates.

In all of the studies, mean-level accuracy depended on the level of actual donation. In only one of the studies was the overall mean indirect measure more accurate. The discriminability was always greater or equivalent for self- versus other-measures: in 
no case were the correlations between indirect and actual measures higher than those between direct and actual measures. Furthermore, none of the manipulations increased the accuracy of indirect measures, even though projection should have had that effect. The studies overall show that indirect measures do not seem to be better measures than direct measures of donation behavior, and projection does not seem to operate to the extent previous researchers have assumed. 


\section{Study 1}

Study 1 measured self- and other- estimates of donations to the Red Cross, as well as actual donations made to the organization. The donation range was $\$ 0$ to $\$ 3.00$.

\section{MeThod}

\section{Participants and design}

Eighty-two undergraduate students (62.2\% female, average age 20.6 years) participated in Study 1 in exchange for extra course credit. Participants were randomly assigned to either the donation condition, in which they gave self, other, and actual judgments, or to the control condition in which they only gave actual judgments.

\section{Procedure}

Participants in the control condition were instructed to find an envelope containing three dollars behind their laptop screen, and were told that the three dollars was their money. Participants then received a brief description of the Red Cross: "The Red Cross is a humanitarian organization that provides emergency assistance, disaster relief and education to alleviate human suffering in the face of emergencies by mobilizing the power of volunteers and the generosity of donors." They were also given the instruction that they could donate all or a portion of their money to the Red Cross if they wished.

The instructions were designed to present a perfectly anonymous environment. First, participants were told that to make their donation decision, they would go one by one to another empty room across from the one where they started the study. Second, I 
emphasized they could put their donation in the collection box in the donation room, either with or without the envelope containing their three dollars. I gave this instruction to avoid suspicion that donation amounts were being tracked in marked envelopes. Third, I instructed them to hide any leftover dollars by putting them in their pocket or in the envelope so that the proctor in the main room could not observe how much they were donating. After their donation decision, participants came back to their computers in the main room. To enable participants to answer and donate in fifty cent increments, they could exchange a one-dollar bill with two fifty-cent pieces via a separate exchange box.

In the donation condition, at the onset of the study, I told participants that I was going to describe a hypothetical study and ask them how they would behave in that study. I then gave them the written instructions that were given to participants in the control condition, except that I did not indicate where the three dollars was located or where the donation room was located. This addition was to prevent participants from finding the envelope and suspecting that I would ask them to actually donate later. I told them only that if they were to participate in such a hypothetical study, they would receive instructions about receiving an envelope with three dollars in it and the remaining instructions about making the donation. After reading the instructions, they answered the two questions below, the order of which was counterbalanced:

Direct question: "How much would you donate out of your \$3.00? Please indicate the amount you would donate to the Red Cross."

Indirect question: "How much do you think other students in this room would donate on average, out of their \$3.00? Please indicate the amount you think other students would donate on average to the Red Cross." 
After answering the two questions, participants in the donation condition were told that they would really participate in the study I had just described, and that the instructions were the actual instructions, not merely hypothetical. They received the full instructions that included information about the location of an envelope containing three dollars and the location of a separate empty donation room where they would put donation money in a collection box. They then went to the donation room and made their donation decisions, just as participants in the control condition had.

Finally, in order to check the extent to which participants were suspicious that I could track their donation amounts, I asked how possible they thought it was that I would know with $100 \%$ confidence the exact amount of their donation, using a 7-point scale (1=absolutely possible to know, 7=absolutely impossible to know). If they answered "absolutely possible to know," I asked a follow-up question asking why they thought I was able to know the donation amount with $100 \%$ confidence. Next, participants received demographic questions and a question asking the study's purpose.

\section{RESULTS}

\section{Suspicion checks}

Seven participants thought it was absolutely possible that I could know their actual donation amounts. Two students suspected the use of cameras and were excluded from further analysis; however, including them did not changed the results. Two students thought I could know their amount because their donation amounts were consistent with their answers. The answers from the other three students were not based on logic (e.g., "Science man."). No participants mentioned serial numbers as a way to track their donation amount. 


\section{The influence of pre-estimation on actual donation}

Participants in the donation condition answered some questions about their future behavior before engaging in their actual behavior, and sometimes answering questions about behavioral intention increases the likelihood of performing the target behavior (Morwitz \& Fitzsimons, 2004). To test for the mere measurement effect in my data, I compared actual donations between the donation and control conditions. The actual donation in the donation condition $(M=1.99)$ was not significantly different from that of the control condition $(M=1.95 ; F(1,79)=.02, p>.89)$. I also tested whether the distributions of responses within the two conditions were statistically different. A Wilcoxon test indicated that the two conditions were similar in their distribution $(Z=.05$, $p>$.96). These results suggest that in my set-up, answering direct and indirect questions did not influence actual donations in the donation condition. The following analyses focus on the donation condition.

\section{Mean-level accuracy}

For mean-level analyses, I used a simultaneously fit hierarchical mixed model with a 2 (self versus other) within-subjects design. I tested both differences between selfand other-estimates and significant differences in the deviations between each of them and actual behavior. 


\section{Estimates}

There was a main effect of self versus other on estimates $(F(1,41)=10.25, p<$ .003 ); consistent with prior research on the better than average effect, respondents gave higher donation numbers for themselves $(M=\$ 2.39)$ versus others $(M=\$ 1.95)$.

\section{Deviations from Actual}

The mean difference between self-estimates and actual donations $(M=\$ 1.99)$ was significantly different from $0(M=\$ 0.40, F(1,41)=4.83, p<.03)$ but the mean difference between other-estimates and actual donations was not significantly different from $0(M=\$ 0.04, F(1,41)=.04, p>.85)$. This enhanced accuracy for indirect versus direct measures was significant $(F(1,41)=10.25, p<.003)$. Thus, for this sample, average other-estimates were closer to average actual donation amounts than average self-estimates.

\begin{tabular}{lcc}
\hline & Means & Correlations with actual behavior \\
\hline Self-estimates & 2.39 & .61 \\
Other-estimates & 1.95 & .31 \\
Actual donations & 1.99 & \\
\hline
\end{tabular}

Table 2: $\quad$ Study 1 - Mean Estimates/Actual Responses and Correlations of Estimates with Actual Behavior 


\section{Correlational accuracy}

A Hotelling test for differences between correlations showed that self-estimates were significantly more highly positively correlated $(r=.61)$ with actual behavior than were other-estimates $(r=.31, t(39)=2.38, p<.02)$.

\section{Slopes}

An important aspect of my methodology is that I take individual measures of self, other-, and actual for each participant. Thus, I can test not only for overall mean differences but also for whether patterns of self- /other- estimates versus actual values vary depending on whether the value is high or low (i.e., on the level of actual donation). So, is the pattern when comparing mean accuracy to actual values different at different levels or is it uniform across the entire range of values/donations? It is part of my research aim to show that in fact this type of interaction underlies results obtained by mean-level data and to show that there is no overall pattern whereby mean self- or otherestimates always serve as better predictors of actual donations. To that end, I used two hierarchical mixed models using self/other and actual as predictors: the first used estimates of donations as the dependent variable; the other used deviations from actual donations as the dependent variable.

When the dependent variable was estimates of donation levels, the interaction between self/other and actual was significant $(F(1,40)=6.57, p<.01)$, indicating that the slope of the self-estimate line $(\beta=.45)$ was significantly greater than the slope of the other-estimate line $(\beta=.20)$. 


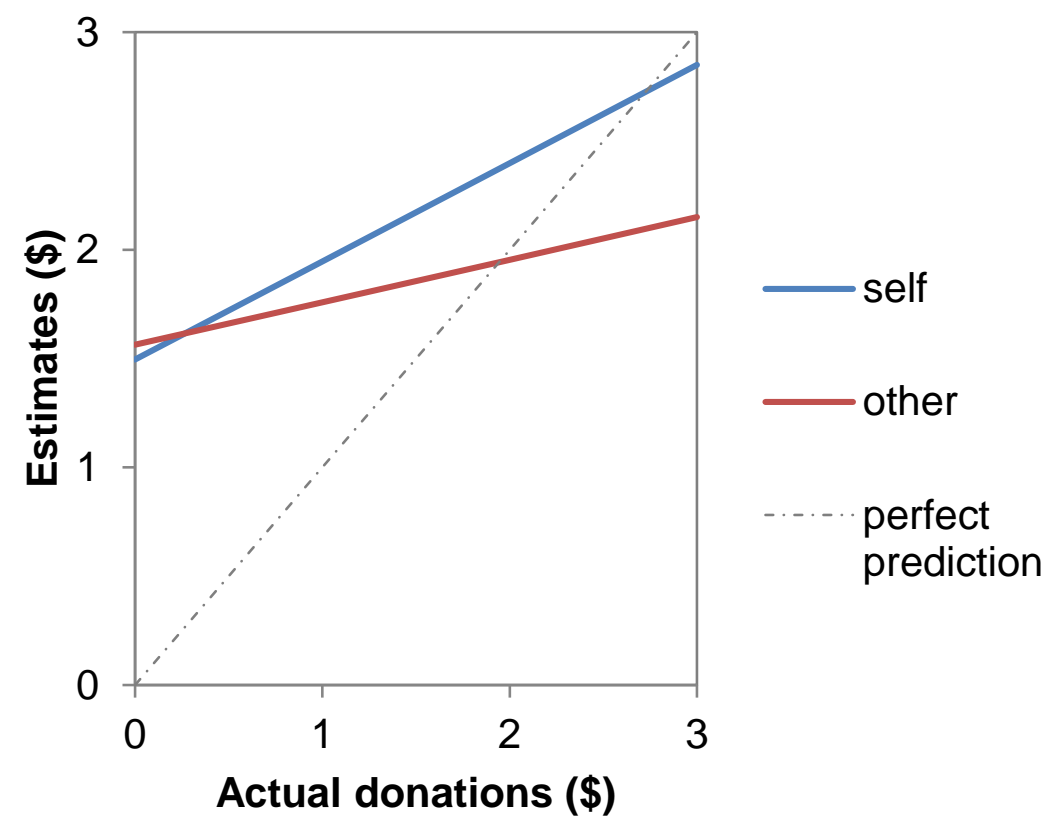

Figure 2: $\quad$ Study 1 - Self- and Other- Estimate Lines

When the dependent variable was the deviation from actual donation levels, the interaction between self/other and actual was significant $(F(1,40)=6.57, p<.01)$, indicating that the slope of the self-estimate line is substantially more similar to the slope of the perfect prediction line, the slope of which is 1 , than to the slope of the otherestimate line and that the relative accuracy of self- versus other- deviations depended on the level of actual donation. Spotlighting a donation level of zero (0) showed that at the lowest level, self-deviations were not different from other-deviations $(F(1,40)=.08, p>$ .78). That is, accuracy was not different. At a donation level of 3 , self-estimates were more accurate than other-estimates $(F(1,40)=18.20, \mathrm{p}<.0001)$.

I conducted a floodlight analysis (Spiller, Fitzsimons, Lynch Jr, \& McClelland, 2013) to identify the Johnson-Neyman points, which in these data are the borders between regions of actual donations where the simple effect is significant and where it is 
not. This analysis reveals three significant Johnson-Neyman points: actual $=1.38,2.00$, and 2.54. Below 1.38, there was no difference; between 1.38 and 2 the indirect measures were closer to actual donations than direct; and from 2.54 to 3.00 the direct measures were closer to actual donations than were the indirect measures.

In other words, the relative mean-level accuracy flips across the range of data, with direct measures being more accurate toward the upper part of the range and indirect either being more accurate or equally accurate toward the lower level of the range. All of my studies will show this same interaction, and as outlined in the introduction, this interaction is consistent with the seeming lack of cohesion in previous mean-level findings.

\section{DISCUSSION}

This first study illustrates that correlation results and mean-level results can give different answers to the question, "Are other- estimates more accurate in predicting actual donation behavior?" For this study, other-estimates were closer on average to the mean actual donation amount but self-estimates were more highly correlated with actual donations. I could also calculate absolute deviations to measure how far away the reported responses were from the actual responses regardless of direction. The absolute deviation of self-estimates $(M=.55)$ was significantly lower than that of other-estimates $(M=.99 ; F(1,41)=10.25, p<.003)$, indicating that self-estimates were closer in distance to actual responses.

These results are inconsistent with the prediction of projection-based indirect question proponents who would suggest that projection would result in responses to 
indirect questions being closer to actual behavior not only using mean-level measures but also using correlational measures.

Why was the mean for indirect measures closer to actual donations in this study? The significant interaction with actual donation levels shows that the relative accuracy of the mean other-estimate response depends completely on the distribution of values. Given the donations were on average small in this study with such a small range of possible donation amounts, the indirect measures were closer on average to actual donations. As I will show, the results for average accuracy vary across studies depending on the distribution of values, but correlational results do not. 


\section{Study 2}

In Study 1, I found that direct questions performed better than indirect questions at predicting actual donations. However, one might wonder whether this would hold true when people are motivated to exaggerate more because of greater social pressure. One of the reasons why projective technique theorists believe that direct questions are worse than indirect questions at identifying an individual's actual behavior is that they believe that when people answer direct questions about their intentions or behavior, they exaggerate their answers to look more socially desirable. Therefore, even if direct questions perform better in normal situations, like the one presented in Study, indirect questions might perform better when added social pressure could be expected to lead people to exaggerate to make themselves look good. Thus, in Study 2, I manipulated social pressure to examine whether greater exaggeration due to greater social pressure would result in indirect questions performing better than direct questions.

In this study, I used a single person as a projection target (i.e., a typical college student), in case something in the wording of previous questions suppressed accuracy. A "typical" person (e.g., typical college student) or an "average" person (e.g., average American consumer) has been used frequently in the projective technique literature (e.g., Fisher, 1993; Luchs et al., 2010; Lusk \& Norwood, 2010; Sinha \& Mandel, 2008) and may make it easier for participants to project their own propensities. The indirect question used in Study 2 was, "If you participated in this study, how much do you think a typical college student would donate out of his/her \$6.00?"

In this study, I no longer included a control condition since I had confirmed in Study 1 that there was no mere measurement effect. I used the United Way instead of the 
Red Cross. The brief description of the United Way included in the instructions was "The United Way is engaged in nearly 1,800 communities across more than 40 countries and territories worldwide. It focuses on improving education, strengthening financial stability, and making communities healthier, the building blocks for a good life and a strong community."

Since in Study 1 a few students were suspicious because they thought there was a camera in the separate donation room, the instructions in Studies 2 through 4 additionally included "There is no person or camera to observe your donation in the donation room." I did not provide the fifty-cent piece exchange option because only a few participants in Study 1 used it. Although I eliminated this exchange option, there were still seven possible donation options (zero donation plus up to six dollars), just as in Study 1, but with a higher maximum.

\section{METHOD}

\section{Participants and design}

One hundred and twenty-seven undergraduate students $(63.8 \%$ females, average age 20.6 years) participated in Study 3 in exchange for extra course credit. Study 3 used a 2 (self versus other) x 2 (exaggerate-more versus exaggerate-less) design. The question type factor was within-subjects, and the anonymity factor was between-subjects.

\section{Procedure}

I did two things to make participants lie more in the exaggerate-more condition: one was to prime participants to be more motivated to act in a more socially desirable 
manner; the other was to have participants make public to other participants how much they themselves would donate.

To prime participants, I asked them to complete a seemingly unrelated study before my main donation study. In the study, participants were told that the researchers were interested in participants' memory capacity. They then were given a sentence to memorize and were told that they would be asked to type the underlined part of the sentence on the next page. The sentence given to participants and its underlined part were "People like people who they think are generous (even if it is not true)" in the exaggeratemore condition and "The goal is for you to know yourself and be honest with yourself even when you are not as generous as you could be" in the exaggerate-less condition. After they completed this memory task, participants were guided to the next study.

The next study is the main donation study, in which, as in the donation condition of Study 1, participants first answered direct and indirect questions about donations to the United Way and then made donation decisions with the six dollars that was given to them. When they answered direct questions, participants in the exaggerate-more condition were asked to write their donation amounts on a post-it note and put the note on a board attached to a pole standing in front of each participant's seat so that other participants could see what was written on the post-it note. The purpose of this procedure was to increase the likelihood of lying by stimulating the motivation to manage impressions. However, the point when participants would see each other's post-it notes had to be postponed until everybody completed making actual donations because if participants had been exposed to what other participants wrote as their donation amounts on post-it notes, they could have changed their estimates about their own donations, estimates about others' donations, and their actual donations. Thus, I asked participants to 
cover their written amounts with a sheet that was attached to each board until told them to uncover it.

Participants in the exaggerate-less condition were also asked to write their donation amounts on a post-it note, but rather than putting the note on a board, they were asked to fold it and keep it to take with them so that nobody could see it.

Here are the instructions used in the direct condition.

"If you participated in this study, how much would you donate to the United Way out of your $\$ 6.00$ ?

You see a small sheet of paper with the word "cover" printed on it. If you lift the sheet up, you will find a yellow post-it note.

[Take down the post-it and write down how much you would donate to the United Way out of your $\$ 6.00$ on it. Then, put the post-it note back where it was. At the end of this session, you will be asked to lift the cover so that other participants can see what you have written on the post-it note and you can see what other participants have written. Until you are told to lift up the cover sheet, please make sure the post-it remains covered up. (for the exaggerate-more condition) / Take down the post-it and write down how much you would donate to the United Way out of your $\$ 6.00$ and fold it. You will take the post-it with you so nobody can see it. (for the exaggerate-less condition)]

Also, please indicate below the amount you wrote that you would donate to the United Way out of your \$6.00.”

The indirect question was "How much would a typical UT student donate out of his/her \$6.00? Please indicate the amount he or she would donate to the United Way."

After participants answered these direct and indirect questions, as in Studies 1 and 2, they completed unrelated filler tasks and then were told that they would really 
participate in the study that had been suggested as a hypothetical study. They then were informed of the actual location of an envelope containing six dollars and the location of a donation room. They then went to the donation room and made their donation decisions. They then answered the same suspicion-check question as in Study 1. At the end of the sessions, participants in the exaggerate-more condition were asked to lift the "cover" sheet so that they could see each other's amounts on the post-it notes. I did not randomly assign individual participants to either the exaggerate-more or exaggerate-less condition, but rather randomly assigned six sessions to one of the two conditions so that everybody in the same session would see all other participants behave in the same way as themselves. This was done to prevent participants from getting confused by observing other participants engaging in different behavior. For example, participants in the exaggerate-less condition might have been confused if they had found that some participants were putting their written post-it notes on boards rather than keeping them. This assignment procedure resulted in 61 participants in the exaggerate-more condition and 66 participants in the exaggerate-less condition.

\section{RESUlTS}

\section{Suspicion checks}

One participant who suspected the use of cameras was excluded from analysis; however, including that participant did not change the results. 


\section{Mean-level accuracy}

For the mean-level analyses, I used a simultaneously fit hierarchical mixed model with a 2 (self versus other) within-subjects factor and a 2 (exaggerate-more versus exaggerate-less) between-subjects factor.

\section{Estimates}

There was a main effect of self versus other on estimates $(F(1,124)=23.61, p<$ .0001); consistent with prior research, participants gave higher donation numbers for themselves $(M=\$ 3.65)$ versus others $(M=\$ 2.81)$. There was no main effect of exaggerate-more versus exaggerate-less $(F(1,124)=1.02, p>.31)$. There was a significant interaction effect between self/other and exaggerate-more/exaggerate-less $(F(1,124)=4.48, p<.04)$ : the amounts that participants said they would donate were greater when they were required to make public how much they would donate to other participants $(M=\$ 4.02)$ than when they were not $(M=\$ 3.32 ; F(1,124)=3.64, p<$ .058); however, their estimates about other people's donations did not differ regardless of whether participants could see others' donation amounts on post-it notes $(M$ exaggerate-more $=$ $\left.\$ 2.78, M_{\text {exaggerate-less }}=\$ 2.83 ; F(1,124)=.02, p>.89\right)$. Actual donations did not differ between the exaggerate-more and exaggerate-less conditions $\left(M_{\text {exaggerate-more }}=\$ 3.87, M\right.$ exaggerate-less $=\$ 3.24 ; F(1,124)=1.95, p>.16)$. In sum, manipulation of social pressure that was meant to make participants exaggerate their intentions only increased selfestimates, but did not increase other-estimates or actual donations. 


\section{Deviations from Actual}

Overall, the mean difference between self-estimates and actual donations $(M=$ $\$ 0.11$ ) was marginally significantly smaller than the mean difference between otherestimates and actual donations $(M=\$ 0.73, F(1,124)=2.82, p<.096)$. Hence, average self-estimates were closer to actual donations than average other-estimates, although only to a marginally significant degree.

\begin{tabular}{lcccc}
\hline & \multicolumn{2}{c}{ Exaggerate-more } & \multicolumn{2}{c}{ Exaggerate-less } \\
\cline { 2 - 5 } & Means & Correlations & Means & Correlations \\
\hline Self-estimates & 4.02 & .46 & 3.32 & .66 \\
\hline Other-estimates & 2.78 & .31 & 2.83 & .45 \\
\hline Actual behavior & 3.87 & & 3.24 & \\
\hline
\end{tabular}

Table 3: $\quad$ Study 2 - Mean Estimates/Actual Donations and Correlations of Estimates with Actual Donations

\section{Slopes}

I ran a hierarchical mixed model with estimates as the dependent variable and actual, self/other, and exaggerate-more/exaggerate-less as predictors. The two-way interaction between self/other and exaggerate-more/exaggerate-less was marginally significant $(F(1,122)=3.16, p<.08)$, indicating that self-estimates in the exaggeratemore condition were greater than in the exaggerate-less condition $(F(1,122)=3.64, p<$ $.06)$, whereas other-estimates were not different in the two conditions $(F(1,122)=.07, p$ $>$.78), essentially the same as results obtained from mean-level data. Hence, the selfestimate line in the exaggerate-more condition was overall higher than the self-estimate 
line in the exaggerate-less condition. The two-way interaction between self/other estimates and actual donations was significant $(\mathrm{F}(1,122)=10.54, p<.002)$, indicating that the slope of the self-estimate line $(\beta=.50)$ was significantly greater than the slope of the other-estimate line $(\beta=.28)$ as in Study 1. The three-way interaction between self/other, actual, and exaggerate-more/exaggerate-less was not significant $(F(1,122)=$ $.40, p>.53$ ) indicating that none of the slopes of self- or other-estimate lines were significantly different between the exaggerate-more and exaggerate-less conditions. Taken together, the results indicate that manipulation of social pressure led people to exaggerate more so the self-line in the exaggerate-more condition was higher than in the exaggerate-less condition, but this did not make the other-estimate line steeper. In other words, the manipulation did not result in improving the accuracy of other-estimates over self-estimates.

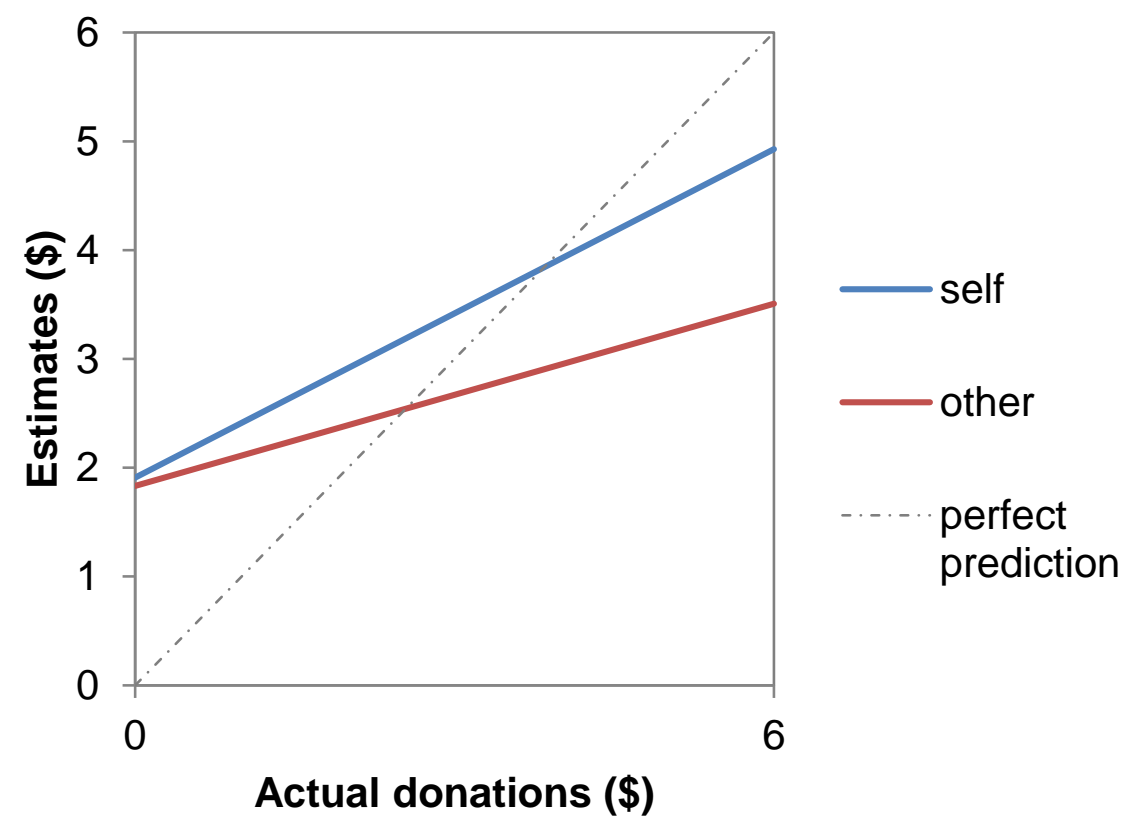

Figure 3: $\quad$ Study 2 - Self- and Other- Estimate Lines 
I ran a hierarchical mixed model with deviations from actual donations as the dependent variable and actual, self/other, and exaggerate-more/exaggerate-less as predictors. There was also a significant two-way interaction between self/other and actual $(F(1,122)=10.54, p<.002)$, which means that the relative accuracy of self- versus other- deviations depended on the level of actual donations. The interaction between self/other estimates and actual donations was significant $(F(1,40)=6.57, p<.01)$, but the three-way interaction between actual, self/other, and exaggerate-more/exaggerate-less was not significant $(F(1,122)=.40, p>.53)$ indicating that the slope of the self-estimate line is substantially more similar to the slope of the perfect prediction line than to the slope of the other-estimate line, regardless of whether it was in the exaggerate-more condition or in the exaggerate-less condition. Spotlighting a donation level of zero showed that self-deviations $(M=\$ 1.91)$ were not different from other-deviations $(M=$ $\$ 1.83 ; F(1,122)=.06, p>.80)$. At a donation level of 6 , self-deviations $(M=\$ 1.07)$ were smaller than other-deviations $(M=\$ 2.49 ; F(1,122)=35.42, p<.0001)$, which means self-estimates were significantly closer to actual donations than other-estimates. The floodlight analysis showed that the Johnson-Neyman point occurred at actual $=1.60$ $(F(1,122)=3.90, p=.05)$, indicating that at actual donations $<1.60$, deviations between self-estimates and actual donations were not significantly different from deviations between other-estimates and actual donations and above 1.60, they were significantly different. 


\section{DiscUSSION}

As expected, participants exaggerated their self-reporting about how much they would donate when other people could see their donation amounts. However, that exaggeration did not lead to indirect questions performing better than direct questions at predicting actual donations. Of course, theoretically, it is possible that people would exaggerate self-estimates to a greater extent if they were placed under even greater social pressure than in Study 2, in which case their self-estimates might differ more from their actual donations than their other-estimates. To be able to prove the validity of the projective technique theory, other-estimates should not only be closer to actual donations at the mean-level but they should also be more highly correlated with actual donations. Therefore, even if greater social pressure resulted in other-estimates being closer to actual donations than self-estimates, this alone would still not constitute evidence that people project, but rather to show that, social pressure would also have to make the otherestimate line steeper. 


\section{Study 3}

In Study 3, I manipulated the similarity of projection targets by using two different projection targets in indirect questions: One was a more similar target, an economics major, and the other was a less similar target, a student in social work. In a pre-test, it was confirmed that the two targets were different in the degree to which participants felt similarity with the target: people thought they were more similar to an economics major $(M=4.18)$ than to a student in social work $(M=3.17 ; F(1,81)=13.58$, $p<.001)$.). Prior research says that people project more onto a similar other than onto a dissimilar other (Ames, 2004; Jenkins, Macrae, \& Mitchell, 2008). If prior research findings are true, we should see a steeper other-estimate line when the projection target is an economics major. However, since my theory suggests that people don't project, I expected that there would be no difference in the slopes of the other-estimate lines between the two targets.

The two targets were also different in perceptions people had about the targets' generosity: people thought a student in social work would be more generous $(M=4.52)$ than an economics major $(M=3.26 ; F(1,38)=7.26, p<.01)$. Thus, I expected that the other-estimate line for a student in social work would be overall higher than that for an economics major.

\section{METHOD}

\section{Participants and design}

Two hundred and ten undergraduate students (51.2\% females, average age 21.03 years) participated in Study 3 in exchange for extra course credit. Study 3 used a 2 (self 
versus other) x 2 (economics versus social work) design. The question type variable was within-subjects, and the projection target's major variable was between-subjects.

\section{Procedure}

As in other studies, participants first received instructions about a hypothetical study and answered direct and indirect questions about donations to the United Way. The direct question was "How much would you donate out of your \$6.00? Please indicate the amount you would donate to the United Way." The indirect question depended on the condition identifying the projection target's major, and was "How much would [an economics major / a student in social work] at UT donate out of his/her \$6.00? Please indicate the amount he or she would donate to the United Way."

Participants then completed unrelated filler tasks. After the filler tasks, participants were told that they would really participate in the study for which they had already indicated hypothetical donation amounts for themselves and a projection target. They received full instructions that included information about the location of an envelope containing six dollars and the location of a donation room. They then went to the donation room and made their donation decisions. They then answered the suspicioncheck question as in Studies 1 and 2.

\section{RESULTS}

\section{Suspicion checks}

Six participants were excluded from further analysis because they were suspicious; however, including them did not change the results. Two students suspected the use of cameras. Three students suspected some markings on money and one 
participant mentioned I could have written the serial numbers of each bill to track their donation amount.

\section{Mean-level accuracy}

For the mean-level analyses, I used a simultaneously fit hierarchical mixed model with a 2 (self versus other) within-subjects factor and a 2 (economics versus social work) between-subjects factor.

\section{Estimates}

There was a main effect of economics major versus social work student $(F(1,202)$ $=12.93, p<.001)$ : participants estimated higher donation numbers for a student in social work $(M=\$ 3.85)$ than those for an economics major $(M=\$ 2.86)$. There was no main effect of self versus other on estimates $(F(1,202)=.01, p>.90)$ : self-estimates $(M=$ \$3.35) were not different from other-estimates $(M=\$ 3.36)$. There was a significant interaction effect between self/other and economics/social work $(F(1,202)=37.76, p<$ .0001): participants said that an economics major would donate less than they themselves would $\left(M_{\text {self }}=\$ 3.25, M_{\text {other }}=\$ 2.48 ; F(1,202)=18.17, p<.0001\right)$, but indicated that a student in social work would donate more than they themselves would $\left(M_{\text {self }}=\$ 3.45\right.$, $\left.M_{\text {other }}=\$ 4.25 ; F(1,202)=19.60, p<.0001\right)$. Actual donations were not different when the projection target was an economics major versus when it was a student in social work $(F(1,202)=.15, p>.69)$. In sum, the different projection targets changed only otherestimates, but didn’t change self-estimates or actual donations. 


\section{Deviations from Actual}

Overall, the mean difference between self-estimates and actual donations $(M=$ \$0.26) was significantly smaller than the mean difference between other-estimates and actual donations $(M=\$ 0.92, F(1,202)=8.55, p<.005)$. Deviations for an economics major target $(M=\$ 0.78)$ were not significantly different from those for the social work student target $(M=\$ 0.40 ; F(1,202)=2.76, p>.09)$.

\begin{tabular}{lcccc}
\hline & \multicolumn{2}{c}{ Economics } & \multicolumn{2}{c}{ Social work } \\
\cline { 2 - 5 } & Means & Correlations & Means & Correlations \\
\hline Self-estimates & 3.25 & .65 & 3.45 & .65 \\
\hline Other-estimates & 2.48 & .27 & 4.25 & .47 \\
\hline Actual behavior & 3.65 & & 3.57 & \\
\hline
\end{tabular}

Table 4: $\quad$ Study 3 - Mean Estimates/Actual Donations and Correlations of Estimates with Actual Donations

\section{Correlation accuracy}

Actual behavior was more highly correlated with self-estimates than with otherestimates, both in the economics condition $\left(r_{\text {self }}=.65, r_{\text {other }}=.27 ; t(99)=5.53, p<.0001\right)$ and in the social-work condition $\left(r_{\text {self }}=.65, r_{\text {other }}=.47 ; t(99)=3.07, p<.003\right)$.

\section{Slopes}

I ran a hierarchical mixed model with estimates of donations as the dependent variable and actual, self/other, and economics/social work predictors. The two-way interaction between self/other and economics/social work was significant $(F(1,200)=$ $41.21, p<.0001)$, indicating that other-estimates in the social work condition were 
significantly greater than in the economics condition $(F(1,200)=3.64, p<.06)$, whereas self-estimates were not different $(F(1,200)=1.18, p>.27)$, so the other-estimate line in the social work condition was overall higher than the other-estimate line in the economics condition. The two-way interaction between actual and self/other was significant $(F(1$, $200)=45.85, p<.0001)$, indicating that the slope of the self-estimate line $(\beta=.59)$ was significantly greater than the slope of other-estimate line $(\beta=.28)$ as in Studies 1 and 2. The three-way interaction between self/other, actual, and economics/social work was not significant $(F(1,200)=2.00, p>.15)$, indicating that none of the slopes of self- and other-estimate lines were significantly different between the economics and social work conditions. Taken together, the economics/social work factor only changed the overall height of other-estimate lines without changing their slopes.

I ran a hierarchical mixed model with deviations from actual donations as the dependent variable and actual, self/other, and economics/social work predictors. The interaction between self/other estimates and actual donations was significant $(F(1,200)=$ 45.85, $p<.0001$ ), but the three-way interaction between actual donations, self/other estimates, and economics/social work was not significant $(F(1,200)=2.00, p>.15)$ indicating that the slope of the self-estimate line is significantly more similar to the slope of the perfect prediction line than to the slope of the other-estimate line regardless of whether it was in the economics condition or in the social work condition. At a donation level of zero, self-deviations $(M=\$ 1.20)$ were significantly smaller than other-deviations $(M=\$ 2.34 ; F(1,200)=32.08, p<.0001)$. At a donation level of six, self-deviations $(M=$ $\$ 1.26)$ were also smaller than other-deviations $(M=\$ 1.97 ; F(1,200)=20.41, p<.0001)$. These results mean that self-estimates were significantly closer to actual donations than were other-estimates at both donation levels of zero and six. The floodlight analysis showed that the Johnson-Neyman point occurred at actual $=2.94(F(1,200)=3.88, p=$ 
$.05)$ and at actual $=4.47(F(1,200)=3.89, p=.05)$, indicating that self deviations were not significantly different from other deviations between 2.94 and 4.47, but at other donation levels, self-deviations were significantly closer to actual donations than other deviations.

\section{DISCUSSION}

In Study 3, I used two different targets: a student in social work and an economics major. The two targets were different with respect to two factors: similarity to the respondent and the extent to which respondents thought each of the two targets would be generous. According to prior research, one would expect people to project more onto a more similar target (i.e., an economics major) than onto a less similar target (i.e., a student in social work), so the other-estimate line for an economics major would be steeper than that for a social work student. However, in Study 3, the slopes of the otherestimate lines for the two targets were indifferent to this similarity factor. The perceived difference in generosity changed the overall height of other-estimate lines: the otherestimate line for social work was overall higher than that for economics. Prior research did not measure actual behavior, but only measured self- and other-estimates. These prior researchers found a greater correlation between participants' self- and other- estimates when the others were similar to them than when the others were dissimilar to them. With only these correlational results but without actual behavioral data, they then concluded that people project more onto similar others than onto dissimilar others. However, in Study 3, where participants' actual behavioral data was measured as well as their selfand other-estimates, I established that the conclusion of prior research is unfounded. Again, I found no evidence that people project. 


\section{Study 4}

One of the purposes of Study 4 was to address the ceiling effect. In Studies 1 through 3, I saw that larger donors were less likely to exaggerate their donation amounts than smaller donors, even if there was greater social pressure to exaggerate (especially in Study 2). However, some people might challenge this finding by saying it was impossible for six dollar donors to exaggerate their donation amounts to say they would donate more than the six dollars they had: their self-estimates could not exceed the donation ceiling of six dollars. So even if they wanted to exaggerate, they could not do it. Those donating four or five dollars would have room to exaggerate by at least one or two dollars, but unfortunately, I was unable to accurately determine whether these donors did exaggerate or not because so few participants donated four or five dollars in either Study 2 (i.e., 10 participants) or Study 3 (i.e., 7 participants) and so few donated two dollars in Study 1 (i.e., 5 participants). Thus, to tackle this issue, I tried to reduce the number of participants who would donate the maximum amounts out of all possible donations by doing two things. First, I used a relatively less well-known local charity, the Texas Historical Foundation, whereas I used nationally well-known charities such as the Red Cross in Study 1 and the United Way in Studies 2 and 3. Second, I increased the maximum possible donation amount from $\$ 6$ or $\$ 3$ to $\$ 15$ to make it less likely that participants would donate all the money that they received. I applied the experimental procedure in the "lie more" condition of Study 3 because I needed to test whether large donors (e.g., 13 or 14 dollar donors) would exaggerate their donation amounts even under greater social pressure. 


\section{METHOD}

\section{Participants and design}

One hundred and forty-six undergraduate students $(52.7 \%$ females, average age 20.4 years) participated in Study 4 in exchange for extra course credit. Study 4 used a 2 (self versus other) within-subjects design.

\section{Procedure}

Participants received envelopes containing fifteen dollars, significantly more than in Study 3. They went to the separate empty room to make donation decisions. In the room, they saw envelopes with a red dot and envelopes with a blue dot. They were asked to put the amount that they wanted to donate in one of the envelopes with a red dot and put the amount that they wanted to keep in an envelope with a blue dot. They then took the envelopes, left the room, and moved to another place with a die, a red box, and a blue box. They rolled the die. If they rolled a 6 on the die, they were asked to put the red-dot envelope in the red donation box and keep the blue-dot envelope with them. The money in the blue-dot envelope was their money, which they could take with them. If they rolled a number other than 6 , they were asked to return the entire fifteen dollars by putting both envelopes in the blue box. The instructions about this procedure had been given to participants before they went to the donation room, so when they made decisions about how to allocate the fifteen dollars into the two envelopes, they understood that only if they rolled a 6 on a die would the amount they put in the red-dot envelope to donate actually be donated to the Texas Historical Foundation and only then would they be able to keep the money they put in the blue-dot envelope. Even though those who got a number other than 6 on the die returned the money, I still was able to determine how 
much they had decided to donate by checking the amounts in the red-dot envelopes in the blue box. They then were asked to go back to their seats and complete the remaining part of the study, which included answering the suspicion-check question.

Before they received fifteen dollars, as in the exaggerate-more condition of Study 3, participants had been first primed with the sentence, "People like people who they think are generous (even if it is not true)" and were asked to answer direct and indirect questions as if they were participating in a hypothetical study. They received the same instructions as they would later receive, so they understood that donation decisions would only actually be carried out if the die landed on 6. Hence, participants answered direct and indirect questions with this in mind. When they answered direct questions, they also wrote their donation amounts on post-it notes, put the notes on their boards, and covered the amounts with a sheet. Later, at the end of the sessions, participants lifted the "cover" sheet so that they could see each other's amounts on the post-it notes.

\section{Results}

\section{Suspicion checks}

In Study 4, there were no participants who had reasonable suspicion about the experimental procedure, so no participants were excluded from analysis.

\section{Mean-level accuracy}

I used a simultaneously fit hierarchical mixed model with a 2 (self versus other) within-subjects design. 


\section{Estimates}

Participants gave higher donation numbers for themselves $(M=\$ 7.16)$ versus others $(M=\$ 5.98 ; F(1,145)=13.32, p<.001)$.

\section{Deviations from Actual}

Overall, the mean difference between self-estimates and actual donations $(M=$ $\$ 0.00)$ was significantly smaller than the mean difference between other-estimates and actual donations $(M=\$ 1.18, F(1,144)=13.32, p<.001)$. This means that average selfestimates were significantly closer to actual donations than average other-estimates.

\begin{tabular}{lcc}
\hline & Means & Correlations with actual behavior \\
\hline Self-estimates & 7.16 & .80 \\
Other-estimates & 5.98 & .46 \\
Actual donations & 7.16 & \\
\hline
\end{tabular}

Table 5: $\quad$ Study 4 - Mean Estimates/Actual Donations and Correlations of Estimates with Actual Donations

\section{Correlation accuracy}

Actual behavior was more highly correlated with self-estimates $(r=.80)$ than with other-estimates $(r=.46 ; t(81)=5.80, p<.0001)$.

\section{Slopes}

I ran a hierarchical mixed model with estimates of donations as the dependent variable and actual donations and self/other as predictors. The two-way interaction between actual and self/other was significant $(F(1,144)=56.72, p<.0001)$, indicating 
that the slope of the self-estimate line $(\beta=.77)$ was significantly greater than the slope of the other-estimate line $(\beta=.39)$, as was the case in Studies 1 through 3 .

I ran a hierarchical mixed model with deviations from actual donations as the dependent variable and actual donations and self/other estimates as predictors. The interaction between self/other estimates and actual donations was significant $(F(1,144)=$ $56.72, p<.0001$ ), indicating that the slope of the self-estimate line is substantially more similar to the slope of the perfect prediction line than to the slope of the other-estimate line and that the relative accuracy of self- versus other- deviations depended on the level of actual donations. A spotlight at a donation level of zero showed self-deviations $(M=$ $\$ 1.62)$ were significantly smaller than other-deviations $(M=\$ 3.20 ; F(1,144)=11.86, p$ $<.001)$. At a donation level of six, self-deviations $(M=\$ 1.77)$ were also smaller than other-deviations $(M=\$ 5.98 ; F(1,144)=74.63, p<.0001)$. Hence, self-estimates were significantly closer to actual donations than other-estimates at both donation levels of zero and six. The floodlight analysis showed that the Johnson-Neyman point occurred at actual $=2.15(F(1,144)=3.91, p=.05)$ and at actual $=6.80(F(1,144)=3.88, p=.05)$, indicating that self deviations were not significantly different from other deviations between 2.15 and 6.80 , but at other donation levels, self deviations were significantly closer to actual donations than other deviations.

\section{DISCUSSION}

One limitation in studies 1 through 3 is the ceiling effect. About $50 \%$ of participants in studies 1 through 3 donated the maximum amounts given to them (i.e., three dollars in Study 1 and six dollars in Studies 2 and 3). In Study 4, the maximum donation amount was increased from three or six dollars to fifteen dollars to reduce the 
percentage of participants who would donate the maximum. In Study 4, the percentage of participants who ended up donating the maximum amount was reduced to about $25 \%$, but the pattern in Studies 1 through 3 still held true in Study 4. 


\section{General Discussion}

It has become commonplace for marketing researchers and other social scientists to ask participants about donations and other ethical questions indirectly by asking them what they think others will do (Chiou et al., 2011; Kaye et al., 2011; Luchs et al., 2010; D. L. Miller \& Thomas, 2005; Sinha \& Mandel, 2008; Steenhaut \& Van Kenhove, 2005; Wilcox et al., 2009). The suggestion to use indirect measures has been made based on the projection theory (Fisher, 1993), but research suggesting the superiority of indirect over direct questioning based on the projection theory has not demonstrated that otherestimates are better predictors of actual behavior than self-estimates.

The present research is the first to examine whether other-estimates are actually better at predicting donation behavior than self-estimates. In addition, instead of measuring and/or making arguments about indirect measures in terms of mean-level data, in these studies I also measure the arguably more important metric of discrimination/correlation. I am able to make these detailed comparisons because I measure both estimates and actual donations for each individual and plot these individual estimates against actual donations instead of averaging them.

I explain why some research using mean-level data (Balcetis \& Dunning, 2013; Epley \& Dunning, 2000) has shown that the mean other-estimate is closer to mean actual

behavior, while other research (D. T. Miller \& Ratner, 1998) reaches the opposite conclusion. I suggest that it cannot categorically be concluded that either the mean selfor mean other-estimate is closer to the mean actual donation, but rather mean-level predictions vary depending upon the distribution of donation amounts of participants. 
My studies show that in terms of correlational accuracy, other-estimates are never better predictors of actual behavior than self-estimates. I found that direct questions eliciting self-estimates were better predictors of actual donations in the face of numerous other factors: single or multiple projection targets, less generous or more generous projection targets, less or greater social pressure, small or relatively large possible donation amounts, and donations to various types of charities.

\section{Contributions}

Indirect questions have seemed like a good idea. Because they appeared to be useful and the projection theory that underlay their use was convincingly relied upon (Fisher, 1993), little research has been done on whether they actually yield the best approximation of donation behavior. Interestingly, the classical projection theory itself that indirect questioning proponents relied upon has been the subject of some controversy (Campbell, 1950; Holmes, 1968) but this controversy has not received significant attention. My research shows that skepticism about the theory may be warranted.

Thus, the most obvious contribution of my research is to issue a warning about the pervasive use of indirect questions for questions about prosocial/ethical behavior such as donation propensity. There appears to be no reason to expect indirect measures to be especially accurate.

Earlier in the paper I outlined the state of the literature before my research in terms of accuracy when using mean-level versus correlational-level data. Proponents of indirect questioning offer different theories: the projection theory (e.g., Fisher, 1993) or the holier-than-thou explanation (e.g., Epley and Dunning 2000) based on Kahneman and Tversky (1979)'s theory on singular and distributional information use. The two research 
streams have the same predictions for mean-level comparisons but make different predictions for correlations. The projection-based proponents predict that actual behavior will be more closely correlated with other-estimates than with self-estimates, whereas proponents of Kahneman and Tversky (1979)'s theory do not. I found self-estimates to be consistently more correlated with actual behavior than other-estimates, which is inconsistent with the expectation of projection-based proponents.

My research also at least starts to shed light on the conundrum in past research of contradictory mean-level findings. When Epley and Dunning (2000) discussed the inconsistency between their findings and those of Miller and Ratner (1998), they proposed that the differences were due to "whether the predicted situation involves hedonic consequences that are immediate or remote." More specifically, participants had to donate money at the very moment they were asked in Epley and Dunning (2000)'s studies, whereas participants in Miller and Ratner (1998)'s studies predicted how they would behave (e.g., donate blood or not) at some time in the future. My studies serve to test this proposed explanation because even though participants in all of my studies donated immediately as in Epley and Dunning (2000)'s studies, my results were closer to Miller and Ratner's (1998). Thus, the inconsistency in research findings is probably not due to timing, although I do acknowledge timing would be a useful avenue for future research. Rather, the inconsistencies seem to be due to the interaction with donation levels and the distribution of responses in particular studies.

\section{FUTURE RESEARCH}

Future research could profitably test whether the patterns I found hold true for other sensitive issues, such as cheating behavior, sexual behavior, or environmentally- 
friendly behavior. In addition, since I have shown that indirect questions, despite their popularity, are of limited usefulness at least for donation behavior predictions, future research might concentrate on how to improve direct estimates. Indirect estimation was developed because of the distrust researchers had for direct measures; this distrust has a long history dating back to the attitude-behavior literature (Eagly \& Chaiken, 1993). My studies show that direct measures of donation behavior are respectable predictors of actual donation behavior, perhaps because the questions I asked were very specific. All of the variables that influence measurement quality (i.e., specificity, time lags, emotionality of the question) might influence the correlations between self-estimates and actual donations compared to the correlations between other-estimates and actual donations. Although I would not expect the accuracy of indirect measures to surpass the accuracy of direct measures even when examined with these variables, at this point their influence is an empirical question to be pursued.

Finally, I would suggest that future researchers measure both mean- and correlation-level accuracy when evaluating measures of respondent behavior. I also would suggest looking at interactions with the level of actual behavior being measured, which has occurred too rarely in studies to date. It was striking how much more I learned about my measures once I examined both mean and correlational data on the one hand, and donation levels on the other. By looking at the relative placement of other- versus self-estimates across the range of behavior, it is possible to get a sense of what drives other-estimates, and to identify when they might be useful for research, although they would not appear to be useful as accurate projective reflections of self-beliefs. For example, people do not seem to believe that others are always less ethical than they themselves are, across the range of ethical behavior. Future research could further elucidate this pattern. 


\section{References}

Ames, D. R. (2004). Strategies for social inference: a similarity contingency model of projection and stereotyping in attribute prevalence estimates. Journal of Personality and Social Psychology, 87(5), 573.

Anik, L., Norton, M. I., \& Ariely, D. (2014). Contingent Match Incentives Increase Donations. Journal of Marketing Research, 51(6), 790-801.

Balcetis, E., \& Dunning, D. (2013). Considering the situation: Why people are better social psychologists than self-psychologists. Self and Identity, 12(1), 1-15.

Balcetis, E., Dunning, D., \& Miller, R. L. (2008). Do collectivists know themselves better than individualists? Cross-cultural studies of the holier than thou phenomenon. Journal of Personality and Social Psychology, 95(6), 1252.

Campbell, D. T. (1950). The indirect assessment of social attitudes. Psychological Bulletin, 47(1), 15.

Chiou, J.-S., Cheng, H.-I., \& Huang, C.-Y. (2011). The effects of artist adoration and perceived risk of getting caught on attitude and intention to pirate music in the United States and Taiwan. Ethics \& Behavior, 21(3), 182-196.

Dunning, D., \& Helzer, E. G. (2014). Beyond the Correlation Coefficient in Studies of Self-Assessment Accuracy Commentary on Zell \& Krizan (2014). Perspectives on Psychological Science, 9(2), 126-130.

Eagly, A. H., \& Chaiken, S. (1993). The psychology of attitudes. Harcourt Brace Jovanovich College Publishers.

Entertainment Software Association. (2015). Essential Facts about the Computer and Video Game Industry 2015. Entertainment Software Association.

Epley, N., \& Dunning, D. (2000). Feeling“ holier than thou": are self-serving assessments produced by errors in self-or social prediction? Journal of Personality and Social Psychology, 79(6), 861.

Fisher, R. J. (1993). Social desirability bias and the validity of indirect questioning. Journal of Consumer Research, 303-315.

Fisher, R. J., \& Tellis, G. J. (1998). Removing social desirability bias with indirect questioning: is the cure worse than the disease? NA-Advances in Consumer Research Volume 25.

Freud, S. (1938). Totem and Taboo in The Basic Writings of Sigmund Freud, ed. Dr. AA Brill (New York, 1938), Esp, 873-877. 
Giving USA. (2015). The Annual Report on Philanthropy for the Year 2015. Glenview, IL: Giving USA Foundation.

Goethals, G. R. (1986). Fabricating and ignoring social reality: Self-serving estimates of consensus. In Relative deprivation and social comparison: The Ontario Symposium (Vol. 4, pp. 135-157). Erlbaum Hills-dale, NJ.

Holmes, D. S. (1968). Dimensions of projection. Psychological Bulletin, 69(4), 248.

Jenkins, A. C., Macrae, C. N., \& Mitchell, J. P. (2008). Repetition suppression of ventromedial prefrontal activity during judgments of self and others. Proceedings of the National Academy of Sciences, 105(11), 4507-4512.

Kahneman, D., \& Tversky, A. (1979). Intuitive prediction: Biases and corrective procedures. Management Science, 12, 313-327.

Katz, D., \& Allport, F. (1931). Students' attitudes. Syracuse, Craftsman.

Kaye, H. S., Jans, L. H., \& Jones, E. C. (2011). Why don't employers hire and retain workers with disabilities? Journal of Occupational Rehabilitation, 21(4), 526-536.

Krosnick, J. A. (1999). Survey research. Annual Review of Psychology, 50(1), 537-567.

Lacetera, N., \& Macis, M. (2010). Do all material incentives for pro-social activities backfire? The response to cash and non-cash incentives for blood donations. Journal of Economic Psychology, 31(4), 738-748.

Lee, S., Winterich, K. P., \& Ross, W. T. (2014). I'm moral, but I won't help you: The distinct roles of empathy and justice in donations. Journal of Consumer Research, 41(3), 678-696.

Luchs, M. G., Naylor, R. W., Irwin, J. R., \& Raghunathan, R. (2010). The sustainability liability: Potential negative effects of ethicality on product preference. Journal of Marketing, 74(5), 18-31.

Lusk, J. L., \& Norwood, F. B. (2010). Direct versus indirect questioning: an application to the well-being of farm animals. Social Indicators Research, 96(3), 551-565.

Miller, D. L., \& Thomas, S. (2005). The impact of relative position and relational closeness on the reporting of unethical acts. Journal of Business Ethics, 61(4), 315-328.

Miller, D. T., \& Ratner, R. K. (1998). The disparity between the actual and assumed power of self-interest. Journal of Personality and Social Psychology, 74(1), 53.

Morwitz, V. G., \& Fitzsimons, G. J. (2004). The mere-measurement effect: Why does measuring intentions change actual behavior? Journal of Consumer Psychology, 14(1), 64-74.

Olynk, N. J., Tonsor, G. T., \& Wolf, C. A. (2010). Consumer willingness to pay for livestock credence attribute claim verification. Journal of Agricultural and Resource Economics, 261-280. 
Ross, L., Greene, D., \& House, P. (1977). The "false consensus effect": An egocentric bias in social perception and attribution processes. Journal of Experimental Social Psychology, 13(3), 279-301.

Sinha, R. K., \& Mandel, N. (2008). Preventing digital music piracy: the carrot or the stick? Journal of Marketing, 72(1), 1-15.

Small, D. A., \& Verrochi, N. M. (2009). The face of need: Facial emotion expression on charity advertisements. Journal of Marketing Research, 46(6), 777-787.

Smith, R. W., Faro, D., \& Burson, K. A. (2013). More for the many: The influence of entitativity on charitable giving. Journal of Consumer Research, 39(5), 961-976.

Spiller, S. A., Fitzsimons, G. J., Lynch Jr, J. G., \& McClelland, G. H. (2013). Spotlights, floodlights, and the magic number zero: Simple effects tests in moderated regression. Journal of Marketing Research, 50(2), 277-288.

Statista. (2016). Smartphones sales in the United States from 2005 to 2016.

Steenhaut, S., \& Van Kenhove, P. (2005). Relationship commitment and ethical consumer behavior in a retail setting: The case of receiving too much change at the checkout. Journal of Business Ethics, 56(4), 335-353.

Teper, R., Inzlicht, M., \& Page-Gould, E. (2011b). Are we more moral than we think? Exploring the role of affect in moral behavior and moral forecasting. Psychological Science, 22(4), 553-558.

Teper, R., Tullett, A. M., Page-Gould, E., \& Inzlicht, M. (2015b). Errors in moral forecasting: Perceptions of affect shape the gap between moral behaviors and moral forecasts. Personality and Social Psychology Bulletin, 41(7), 887-900.

Wilcox, K., Kim, H. M., \& Sen, S. (2009). Why do consumers buy counterfeit luxury brands? Journal of Marketing Research, 46(2), 247-259.

Winterich, K. P., Mittal, V., \& Ross Jr, W. T. (2009). Donation Behavior toward InGroups and Out-Groups: The Role of Gender and Moral Identity. Journal of Consumer Research, 36(2), 199-214. 